\title{
Modularity Curriculum Design and Effective Evaluation Analysis
}

\author{
Ye Ren \\ Economy and Trade Department \\ Zhengzhou Electric Power College \\ Zhengzhou,China \\ Yezi11023@163.com
}

\author{
Sa Xiao \\ Economy and Trade Department \\ Zhengzhou Electric Power College \\ Zhengzhou,China \\ Xiaosa9@sina.com
}

\begin{abstract}
This paper analyzes the goal of modularity teaching curriculum and curriculum module design, and then, the paper establishes a effective evaluation model based on factor analysis and multiple objective decision theory. The aim is to evaluate the implementation of modularity curriculum design effect. Based on the construction and practice of Distribution Practices Curriculum, according to the employable skill frame and requirement of professional skill appraisal, the paper makes effort to reform the teaching model and constructs the modularity curriculum. By establishing the practice modularity teaching system of Distribution Management, the paper brings about a striking effect on teaching and improve the vocational education level. Finally, the paper provides the theoretical direction and operable methods for evaluation analysis in higher vocational education. It is important to train the students to be advanced technical talents in agreement with the development of logistics industry.
\end{abstract}

Keywords- multiple objective decision; factor analysis; modularity curriculum design; vocational education

\section{INTRODUCTION}

In nineteen seventies, the International Labour Organization introduced the modularity teaching, it is to develop field teaching, module teaching mode takes the skills training as the core, and has been widely used in many countries. The teaching method has the features of target, flexibility and practice, and more and more be in attention in education.

The so-called modularity teaching mode is a set of teaching system to design teaching content according to the conception of program modularity and principles, it is fixed in the training objectives guide .According to a certain standard or rule, all the teaching content are divided into several partitions, and make them become relatively independent teaching module, and each teaching module can be combined according to certain rules of selective. Students can choose different modules according to their own interests and occupation orientation, so as to realize the training requirements of different teaching objectives and personnel.

The modularity curriculum design is still in the exploratory study in the present education, here, based on the Distribution Practices Curriculum, this paper designed the modularity teaching system, and then, this paper analyzed the goal of modularity teaching curriculum and curriculum module design, and gave out a combination of factor analysis and multiple objective decision.

\section{Modularity Design Of Distribution Practices CURRICULUM}

Distribution practices is the core curriculum of logistics management specialty of Higher Vocational College, it is a practical skill curriculum and leading curriculum of logistics management major. Teaching aim is to make the students to complete the basic knowledge of logistics management, basic quality training, to master the basic skills, familiar with the basic rules. In the process of teaching, the teaching aim is to cultivate students' knowledge of the business, and to train skilled business skills, and strive to improve the student's occupation character and comprehensive processing capacity of the distribution business, and finally, the aim is to enhance students' post adaptation ability, and achieve zero transition between graduation and employment.

Through designing the teaching module, it can help students to understand and master the distribution form of organization; to understand and master the basic skills of operation; to understand the comprehensive distribution business management regulations; to understand and grasp the order processing task, acceptance of storage tasks, the picking task, the loading and packing task, the replenishment and return task and the delivery task etc.

\section{A. The modularity teaching content Design of Distribution Practices Curriculum}

The curriculum design established the modularity curriculum system based on the task. According to the basic skill requirements for distribution business, the curriculum design made a comprehensive update on the curriculum content and the curriculum system, composed of five teaching modules. Construction of the occupation ability of logistics management is directed by professional practice, take modularity teaching as the carrier, take the student as the main body, emphasize the training of practical ability, organize the teaching process according to the first-line technical staff of logistics posts, implement the hierarchical teaching mode such as "module teaching + project training + practice" .

The teaching form is reformed to be the modularity case teaching. The modularity Distribution Practices Curriculum is shown as the following figure1. 

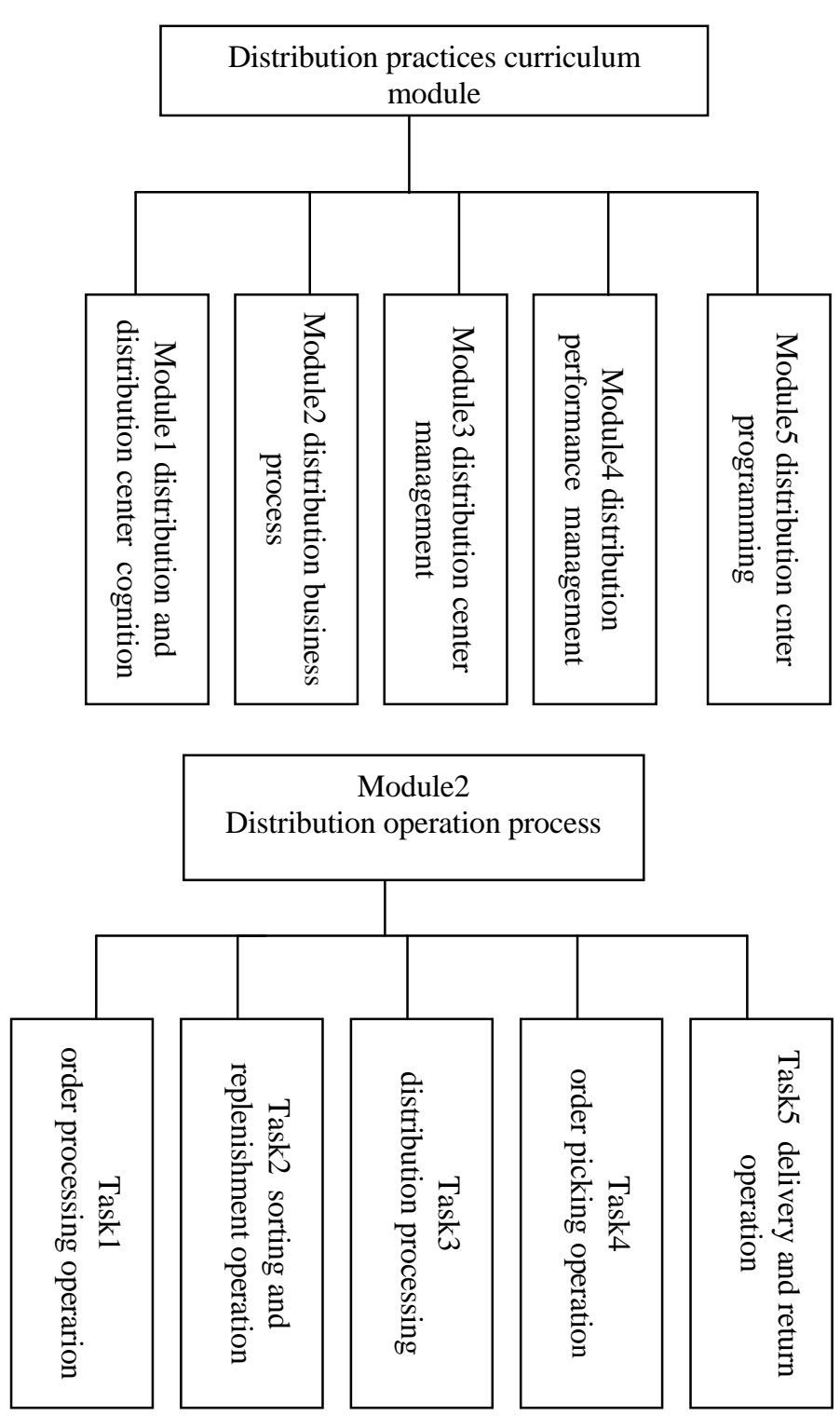

Figure 1. The modularity Distribution Practices Curriculum

\section{B. Practical Training Module in the Simulation Occupation Work Environment}

The practice module aims to train the practical ability. According to the professional logistics management personnel training requirements, in order to train the occupation technical application ability for students, it must have the occupation working environment, under this theory, the simulated supermarket and comprehensive skills laboratory were established a comprehensive logistics and distribution business training software were purchased, the distribution management information system, system operation instruction, business documents, the practice appliance were given out. It can complete the whole process of modern distribution business processing system by simulation training.

During the practical teaching, the practice combines with the distribution operation, students' integration capability such as applying knowledge, manual operation handling problem are cultured. In the teaching processing, relying on the simulation post, the teacher teaches in the logistics comprehensive laboratory for the business training, furthermore, through the integrated distribution business skills training, the students' practical ability are improved, students' practical ability and adaptation ability are strengthened.

This curriculum consists of 78 hours, including 52 hours for theory and 26 hours for practice, practical teaching steps are strengthened to improve the students capacity. In order to strengthen the distribution business process operation for the students, training projects carry out step by step, training aims directly at the application ability of occupation. Firstly, during the theoretical teaching, simple training goes on simultaneously, and then, during the comprehensive training, the modularity project comes from the actual business process of logistics jobs, practice training combines with the distribution practices, the aim focuses on cultivating the students' practical ability.

\section{THE EFFECT EVALUATION METHOD OF THE MODULARITY TEACHING}

The paper gives out a effect evaluation method based on factor analysis and multiple objective decision, it makes the evaluation result more objective.

\section{A. Evaluating Indicator Matrix}

The sample of this model based on evaluation indicator matrix include two types of students. One is based on ordinary training, the other is based on the modularity teaching. By factors analysis, the regression equation is $F_{j}=\beta_{j 1} X_{1}+\beta_{j 2} X_{2}+\cdots+\beta_{j p} X_{m} j=1,2, \cdots, m$,

so we get the evaluation indicator matrix $A$ based on $n$ students including $p$ evaluation factors, here $A=\left[\begin{array}{cccc}a_{11} & a_{12} & \cdots & a_{1 n} \\ a_{21} & a_{22} & \cdots & a_{2 n} \\ \cdots & \cdots & \cdots & \cdots \\ a_{p 1} & a_{p 2} & \cdots & a_{p n}\end{array}\right], a_{i j}$ is the index value indicated as the $j$ th scheme about the ith evaluation factor. The evaluating indicator is divided into three types such as cost, benefit and appropriate measure, in this paper, we adopted the benefit indicators such as rate of employment, rate of obtaining qualification, progression rate, the success rate in the exam, pass rate of training and so on. 


\section{B. The design of weights in multi-objective decision-} making on the basis of evaluation indicator matrix $A$

The paper introduces a benefit evaluating model for the modularity teaching scheme analysis of weights in multiobjective decision-making.

Firstly, we established the optimal scheme $u^{*}$ and the inferior scheme $u_{*}$ based on the indicator values of each scheme.

Let $u^{*}=\left(u_{1}^{*}, u_{2}{ }^{*}, u_{3}{ }^{*}\right), u_{*}=\left(u_{1^{*}}, u_{2^{*}}, u_{3^{*}}\right)$, here , $u_{i}^{*}=\max _{1 \leq j \leq n}\left\{a_{i j}\right\}, u_{i^{*}}=\min _{1 \leq j \leq n}\left\{a_{i j}\right\}$

Secondly, we constructed the relative deviation matrix $R=\left(r_{i j}\right)_{p \times n}, \Delta=\left(\delta_{i j}\right)_{p \times n}$ between each scheme and $u^{*}$

here,

$$
r_{i j}=\frac{\left|u_{i}^{*}-a_{i j}\right|}{\max _{1 \leq j \leq n}\left\{a_{i j}\right\}-\min \left\{a_{i j}\right\}}, \delta_{i j}=\frac{\left|u_{i^{*}}-a_{i j}\right|}{\max _{1 \leq j \leq n}\left\{a_{i j}\right\}-\min \left\{a_{i j}\right\}} .
$$

Finally, we established the weighs of evaluating indicator to compute vectorial angle cosine between the row vector of matrix $R$ and $\Delta$, the result is shown as the following equation: $c_{i}=\frac{\sum_{j=1}^{n} r_{i j} \delta_{i j}}{\sqrt{\sum_{j=1}^{n} r_{i j}^{2}} \sqrt{\sum_{j=1}^{n} \delta_{i j}^{2}}}$, and then, we normalized $c_{i}$ and get the weight vector $\omega=\left(\omega_{1}, \omega_{2}, \omega_{3}\right)$ of $p$ evaluating indicators, here, $\omega_{i}=\frac{c_{i}}{\sum_{i=1}^{p} c_{i}},(i=1,2, \cdots, p)$

C. Solve out the comprehensive assessment value

According to sequence of index data, the article applies fuzzy assessment model to process data, works out comprehensive assessment value of technical proposals, the relative membership degree matrix between each scheme and the optimal scheme is

$$
M=\left[\begin{array}{cccc}
m_{11} & m_{12} & \cdots & m_{1 n} \\
m_{21} & m_{22} & \cdots & m_{2 n} \\
\cdots & \cdots & \cdots & \cdots \\
m_{p 1} & m_{p 2} & \cdots & m_{p n}
\end{array}\right]
$$

Here,

$$
m_{i j}=\frac{c_{i}}{\max _{1 \leq j \leq n}\left\{a_{i j}\right\}} \quad(i=1,2, \cdots, p ; j=1,2 \cdots, n) \quad \text {.so, }
$$
comprehensive assessment value of students is $d_{j}=\sum_{i=1}^{p} \omega_{i} m_{i j}(j=1,2,3, \cdots, n)$, obviously, as $d_{j}$ is bigger, the evaluating value of student is bigger. In this way, we can solve out the average value of the two types of students that including the ordinary student and the modularity teaching training student. According to the average value we can get the difference between the modularity mode and the ordinary mode.

\section{REFERENCES}

[1] Taylor, Lyndal. Reflecting On Teaching :The Benefits Of SelfEvaluation. Assessment \& Evaluation in Higher Education, August, 1994:109-121.

[2] John A.Gretes and Miehel Green. Improving Undergraduate Learning with Computer-Assisted Assessment [ J ] .Journal of Reserch on Computing In Education,2000, Vol 33. No l

[3] Lianhui Liu, Distribution practices, China supplies press,2009.

[4] Ruiping, He. interaction design and implementation of teaching content in web-based course [D], Tianjin Normal University, 2012.3

[5] Jili Kong, Ailan Feng. Construction of Distribution and distribution center course [J], logistics technology, 2012.9

[6] Chen Tan, Researech of classroom instruction evaluation in higher vocational Education colleges in the context of MES,2010.6 